\title{
Research Article \\ Conjugate Heat Transfer of Mixed Convection for Viscoelastic Fluid Past a Stretching Sheet
}

\author{
Kai-Long Hsiao and Guan-Bang Chen \\ Received 18 July 2006; Revised 28 October 2006; Accepted 27 December 2006 \\ Recommended by Kumbakonam Rajagopal
}

A conjugate heat transfer problem of a second-grade viscoelastic fluid past a stretching sheet has been studied. Governing equations include heat conduction equation of a stretching sheet, continuity equation, momentum equation, and energy equation of a second-grade fluid, analyzed by a combination of a series expansion method, the similarity transformation, and a second-order accurate finite-difference method. These solutions are used to iterate with the heat conduction equation of the stretching sheet to obtain distributions of the local convective heat transfer coefficient and the stretching sheet temperature. Ranges of dimensionless parameters, the Prandtl number Pr, the elastic number $E$ and the conduction-convection coefficient $N_{\mathrm{cc}}$ are from 0.001 to $10,0.0001$ to 0.01 , and 0.5 to 2.0 , respectively. A parameter $G$, which is used to represent the dominance of the buoyant effect, is present in governing equations. Results indicated that elastic effect in the flow could increase the local heat transfer coefficient and enhance the heat transfer of a stretching sheet. In addition, same as the results from Newtonian fluid flow and conduction analysis of a stretching sheet, a better heat transfer is obtained with a larger $N_{\mathrm{cc}}, G$, and $E$.

Copyright (c) 2007 K.-L. Hsiao and G.-B. Chen. This is an open access article distributed under the Creative Commons Attribution License, which permits unrestricted use, distribution, and reproduction in any medium, provided the original work is properly cited.

\section{Introduction}

The flow of an incompressible viscous over a boundary layer is important to industrial applications. For instance, it is in the extrusion of a polymer sheet from a die or in the drawing of plastic films. For some of dilutes polymer solutions or polymer fluids, they belong to second-grade fluids, and it is a well-known fact in the studies of non-Newtonian fluid flows [1]. Thus, if we use a non-Newtonian fluid as the coolant of the cooling system, heat exchangers might greatly reduce the required pumping power. Therefore, a 
fundamental analysis of the flow field of non-Newtonian fluids in a boundary layer adjacent to a stretching sheet or an extended surface is very important, and is an essential part in the area of the fluid dynamics and heat transfer. Especially, understanding boundary layer flows and heat transfer of non-Newtonian fluids has become important in recent year. Srivatsava [2], and Rajeswari and Rathna [3] studied the non-Newtonian fluid flow near a stretching sheet. Mishra and Panda [4] analyzed the behavior of second-grade viscoelastic fluids under the influence of a sidewall injection in an entrance region of a pipe flow. Rajagopal et al. [5] studied a Falkner-Skan flow field of a second-grade viscoelastic fluid. Massoudi and Ramezan [6] studied a wedge flow with suction and injection along walls of a wedge by the similarity method and finite-difference calculations. Hsu et al. [7] also studied the flow and heat transfer phenomena of an incompressible second-grade viscoelastic fluid past a wedge with suction or injection. Rajagopal [8] recently wrote an excellent review of boundary layers in nonlinear fluids. These are related studies to the present investigation about second-grade fluids. The viscoelastic nature of a secondgrade fluid is found in some dilute polymer solutions or in polymer fluids. These fluids exhibit both the viscous and elastic characteristics. Same as Newtonian fluids, the viscous property is due to the transport phenomenon of the fluid molecules. The elastic property is due to the chemical structure and configuration of the polymer molecule. The term "elastic" means that the viscoelastic fluid "remembers" where it was. Macromolecules act as small rubber band and tend to snap back when the external forces have removed, and hence produce "elastic recoil" of the fluid. Detailed information of viscoelastic fluid can be found in books of rheology. Rajagopal et al. [5] studied the Falkner-Skan flow of a fluid of second grade. They used the perturbation procedure and finite-difference method for simplifying a nonlinear problem to a quasilinearization problem. All of the above are dealing with forced convection problems. Vajravelu and Soewono [9] solutions to the fourth-order nonlinear systems arise in combined free and forced convection flow of a second-order fluid, over a stretching sheet. The stretching sheet flow of a non-Newtonian fluid is also one of the important flow fields in real world, Garg and Rajagopal [10] had studied its flow fields and Raptis and Takhar [11] had studied the heat transfer of a viscoelastic fluid. Boundary layer flow over a moving continuous solid surface is an important type of flow occurring in several engineering processes. Heat-treated materials traveling between a feed roll and a wind-up roll or materials manufactured by extrusion. Since the pioneering work of Sakiadis [12], many authors have investigated various aspects of the problem. Crane [13] and P. S. Gupta and A. S. Gupta [14] have analyzed the stretching problem with constant surface temperature while Soundalgekar [15] investigated the Stokes problem for a viscoelastic fluid. Siddappa and Khapate [16] for a special class of non-Newtonian fluids known as second-order fluids that are viscoelastic in nature examined this flow. Danberg and Fansler [17] studied the solution for the boundary layer flow past a wall that stretched with a speed proportional to the distance along the wall.

Rajagopal et al. [18] independently examined the same flow as in [16] and obtained similarity solutions of the boundary layer equations numerically for the case of small viscoelastic parameter. It is shown that skin friction decreases with increase in viscoelastic parameter. Dandapat and Gupta [19] examined the same problem with heat transfer. In [19], an exact analytical solution of the nonlinear equation, governing a self-similar flow 
that is consistent with the numerical results in [18], is given and the solutions for the temperature for various values are presented. Later, Cortell [20] extended the work of Dandapat and Gupta [19] to study the heat transfer in an incompressible second-order fluid caused by a stretching sheet with a view of examining the influence of the viscoelastic parameter on heat-transfer characteristics. In the case of fluids of differential type [21], the equations of motion are in general one-order higher than the Navier-Stokes equations and, in general, they need additional boundary conditions to determine the solution completely. These important issues were studied in detail by Rajagopal [21, 22], Rajagopal and Gupta [23] and Rajagopal and Kaloni [24]. In order to clarify these points, a critical review on the boundary conditions, existence, and uniqueness of the solution has been provided by Dunn and Fosdick [25] and Girault and Scott [26]. On the other hand, Abel and Veena [27] investigated a viscoelastic fluid flow and heat transfer in a porous medium over a stretching sheet. Abel et al. [28] studied the effect of heat transfer on MHD viscoelastic fluid over a stretching surface and an important finding was that the effect of viscoelasticity is to decrease dimensionless surface temperature profiles in that flow. Furthermore, Char [29] studied MHD flow of a viscoelastic fluid over a stretching sheet, however, only the thermal diffusion is considered in the energy equation; later, Sarma and Rao [30] analyzed the effects of work due to deformation in that equation. Cortell [31] studied flow and heat transfer of a viscoelastic fluid over a stretching sheet. Sanjayanand and Khan. [32] studied heat and mass transfer in a viscoelastic boundary layer flow over an exponentially stretching sheet. Khan [33] analyzed heat transfer in a viscoelastic fluid flow over a stretching surface with heat source/sink, suction/blowing, and radiation.

The system analyzed in the present study was a stretching sheet in a second-grade viscoelastic fluid flow. Due to the coupling nature between the stretching sheet and the fluid, the present analysis is different from previous researches concerning forced convection about a flat-plate fin. Those studies have dealt primarily with a plate having prescribed convective heat transfer coefficient that yields similar or nonsimilar solutions [34]. There are some related conjugate problems concerning a fin in a Newtonian flow, for instance, a complete model study about the forced convection on a rectangular fin has been investigated by Sparrow and Chyu [35]; the effect of the Prandtl number on the heat transfer from a rectangular fin has been studied by Sundén [36]. In addition, Luikov et al. solved the conjugate forced convective problem along a flat plate both numerically [37] and analytically [38-41]. The analysis of conjugate heat transfer problem encompasses simultaneous solutions for the heat conduction equation for the fin and the boundary layer equations for the adjacent fluid. These solutions are governed by two dimensionless parameters, one of which is termed the conduction-convection number $N_{\mathrm{cc}}$ and the other the Prandtl number Pr.

The above provides the motivation for the present analysis in which we study the flow and heat transfer in an incompressible second-grade fluid caused by a stretching sheet with a view of examining the influence of viscoelasticity on flow and heat transfer characteristics for forced and free convection phenomena. We present a similar analysis using Rajagopal et al.'s [5] method to solve the nonlinear problem. Therefore, in the present investigation, a study has been undertaken to provide a result for the mixed convection 
flow of a second-grade fluid adjacent to a stretching sheet. The buoyant force is important in the present problem due to the differences between the stretching sheet temperature and the fluid temperature. A complicated flow pattern might occur because of the interaction of the buoyancy and the viscoelasticity of the fluid. Thus, considerable efforts directed towards the analysis and the understanding of the problem that characterized by a set of highly nonlinear, coupled partial differential equations. A similar derivation technique has been used and the resulting similar equations have been solved by using the method of similarity. The effects of the viscoelastic parameter $E$, the buoyancy parameter $G$, and the Prandtl number Pr to the momentum and heat transfer on the stretching sheet are discussed in the present study.

\section{Theory and analysis}

An incompressible, homogeneous, non-Newtonian, second-grade fluid having a constitutive equation based on the postulate of gradually fading memory which is suggested by Rivlin and Ericksen [42] is used in the present flow. Furthermore, a thorough discussion of these issues can be found in the critical review of Dunn and Rajagopal [43]. If the fluid of second grade modeled by (2.1) is to be compatible with thermodynamics and is to satisfy the Clausius-Duhem inequality for all motions and the assumption that the specific Helmholtz free energy of the fluid is a minimum when it is locally at rest, the model equation is expressed as follows:

$$
\mathbf{T}=-P \mathbf{I}+\mu \mathbf{A}_{1}+\alpha_{1} \mathbf{A}_{2}+\alpha_{2} \mathbf{A}_{1}^{2}
$$

where $\mathbf{T}$ is the stress tensor, $P$ is the pressure, $\mu$ is the dynamic viscosity, $\alpha_{1}$ and $\alpha_{2}$ are first and second normal stress coefficients that relate to the material modulus and for the present second-grade fluid

$$
\mu \geq 0, \quad \alpha_{1}>0, \quad \alpha_{1}+\alpha_{2}=0 .
$$

The kinematic tensors $\mathbf{A}_{\mathbf{1}}$ and $\mathbf{A}_{\mathbf{2}}$ are defined as

$$
\begin{gathered}
\mathbf{A}_{\mathbf{1}}=\nabla \mathbf{V}+(\nabla \mathbf{V})^{\mathrm{T}}, \\
\mathbf{A}_{\mathbf{2}}=\frac{\mathbf{d} \mathbf{A}_{\mathbf{1}}}{\mathbf{d t}}+\mathbf{A}_{\mathbf{1}}(\nabla \mathbf{V})+(\nabla \mathbf{V})^{\mathrm{T}} \mathbf{A}_{\mathbf{1}},
\end{gathered}
$$

where $\mathbf{V}$ is velocities and $\mathbf{d} / \mathbf{d} \mathbf{t}$ is the material time derivative. As mentioned by Markovitz and Coleman in [44] and by Acrivos in [45], this model is applicable to some dilute polymers. In the present analysis, we consider the flow of a second-grade fluid obeying (2.1) adjacent to a stretching sheet coinciding with the plane $y=0$, the flow being confined to $y>0$. Two equal and opposite forces are applied along the $x$-axis (a positive $x$-axis has been taken vertically and parallel to the direction of gravity). The geometric model is depicted in Figure 2.1. 


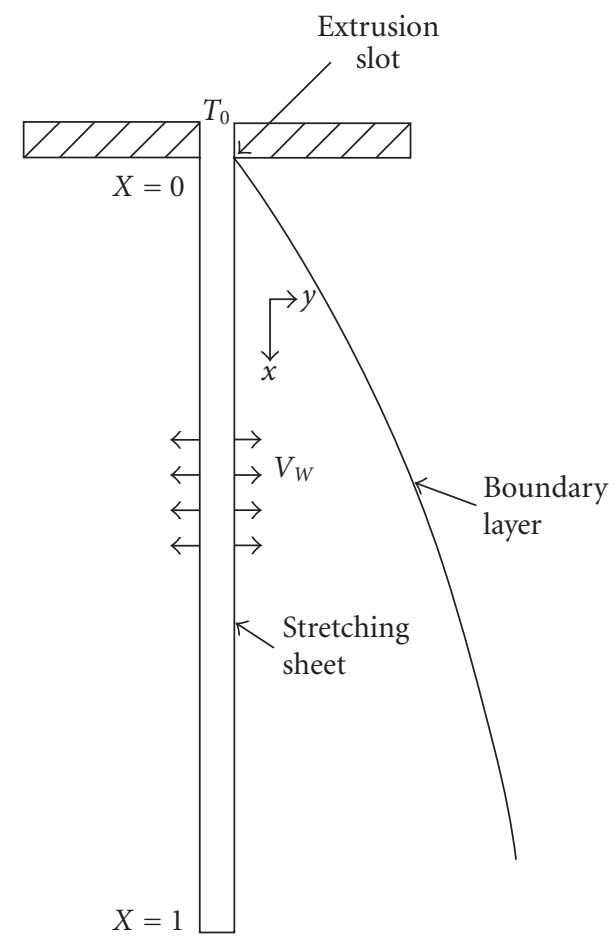

Figure 2.1. A sketch of the physical model.

The steady two-dimensional boundary-layer equations for this flow and heat transfer, in usual notation, are

$$
\begin{gathered}
\frac{\partial u}{\partial x}+\frac{\partial v}{\partial y}=0 \\
u \frac{\partial u}{\partial x}+v \frac{\partial v}{\partial y}=v \frac{\partial^{2} u}{\partial y^{2}}+k_{0}\left[\frac{\partial}{\partial x}\left(u \frac{\partial^{2} u}{\partial y^{2}}\right)+\frac{\partial u}{\partial y} \frac{\partial^{2} v}{\partial y^{2}}+v \frac{\partial^{3} u}{\partial y^{3}}\right]+g_{x} \beta\left(T-T_{\infty}\right) \\
\rho c_{p}\left(u \frac{\partial T}{\partial x}+v \frac{\partial T}{\partial y}\right)=k \frac{\partial^{2} T}{\partial y^{2}}+q\left(T-T_{\infty}\right)
\end{gathered}
$$

In (2.5), we use the Oberbeck-Boussinesq approximation. This has not been rigorously justified even in the case of the classical Navier-Stokes fluid and definitely not in the case of the second grade fluid. Rajagopal at al. provided a justification for the approximation within the full thermodynamical theory for Navier-Stokes fluids [46]. We follow its concept and assume that the form for the Helmholtz potential is similar to that for a Navier-Stokes fluid and that we are ignoring terms due to the normal stress coeffient $\alpha_{1}$ at a small value. It is similar to a Navier-Stokes fluid. At last, (2.5) can use the OberbeckBoussinesq approximation to calculate the free convection problem, in which $u, v$ are the 
velocity components in the $x$ and $y$ directions, $T$ is the temperature, $g_{x}$ is the magnitude of the gravity, $\nu$ is the kinematic viscosity, $k_{0}=\alpha_{1} / \rho$ is coefficient of viscoelasticity, $\beta$ is the coefficient of thermal expansion, $T_{\infty}$ is the temperature of the ambient fluid, $\rho$ is the density, $c_{p}$ is the specific heat at constant pressure, $k$ is the conductivity, and $q$ is the specific heat generation rate. The well-known Boussinesq approximation $\rho-\rho_{\infty}=-\rho \beta\left(T-T_{\infty}\right)$ is used to represent the buoyancy mixed term. The boundary conditions to the problem are

$$
\begin{gathered}
u=B x, \quad v=v_{w}=-(B v)^{1 / 2}\left(m-\frac{1}{m}\right) \quad y=0, \quad B>0, \\
u \longrightarrow 0, \quad \frac{\partial u}{\partial y} \longrightarrow 0 \quad \text { as } y \longrightarrow \infty \\
T=T_{w}=T_{\infty}+A\left(\frac{x}{L}\right) \quad \text { at } y=0, \quad T=T_{\infty} \quad \text { as } y \longrightarrow \infty,
\end{gathered}
$$

where $T_{w}$ and $T_{\infty}$ are constant wall temperature and ambient fluid temperature, $A$ and $B$ are the proportional constants, and $L$ is the characteristic length, respectively. It should be noted that $m>1$ corresponds to suction $\left(v_{w}<0\right)$, where $m<1$ corresponds to blowing $\left(v_{w}>0\right)$. In the case when the parameter $m=1$, the stretching sheet is impermeable. In this study, parameter $m=1$ to simplify the problem in the conjugate heat transfer. A similarity solution for velocity will be obtained if a set of transformations is introduced, such that

$$
\begin{gathered}
u=B x f^{\prime}(\eta), \quad v=-(B \nu)^{1 / 2} f(\eta), \\
\eta=\left(\frac{B}{v}\right)^{1 / 2} y, \quad \theta=\frac{T-T_{\infty}}{T_{w}-T_{\infty}} .
\end{gathered}
$$

Equation (2.8) has satisfied the continuity equation (2.4), Substituting (2.8) into (2.5), we have

$$
f^{\prime 2}-f f^{\prime \prime}=f^{\prime \prime \prime}+k_{1}\left(2 f^{\prime} f^{\prime \prime}\right)+k_{1}\left(2 f^{\prime} f^{\prime \prime \prime}-f^{\prime \prime 2}-f f^{I V}\right)+G \theta
$$

where $k_{1}=\alpha_{1} B / \mu$ is the viscoelastic parameter and $G=g_{x} \beta A / B^{2} L$ is the free convection parameter, where $L$ is the thickness of the stretching sheet. The corresponding boundary conditions become

$$
\begin{gathered}
f=0 \quad f^{\prime}=1 \quad \text { at } \eta=0, \\
f^{\prime} \longrightarrow 0, \quad f^{\prime \prime} \longrightarrow 0 \quad \text { as } \eta \longrightarrow \infty
\end{gathered}
$$

for the prescribed surface temperature. We introduce the dimensionless temperature

$$
\theta(\eta)=\frac{T-T_{\infty}}{T_{w}-T_{\infty}}
$$


Combining the transformations from (2.8), the energy equation (2.6) becomes

$$
\theta^{\prime \prime}+\operatorname{Pr} f \theta^{\prime}-\operatorname{Pr} f^{\prime} \theta=0
$$

where $\operatorname{Pr}=\mu c_{p} / k$ is the Prandtl number. The corresponding thermal boundary conditions are

$$
\begin{gathered}
\theta=1 \quad \text { at } \eta=0, \\
\theta \longrightarrow 0 \quad \text { as } \eta \longrightarrow \infty .
\end{gathered}
$$

The parameters $k, E, \operatorname{Pr}$, and $G$ are the conductivity of the fluid, the viscoelastic parameter, the Prandtl number, and the free convection parameter, respectively. These parameters control variations of the flow and the heat transfer characteristics. In the present study, isothermal condition was considered along the sheet, and it does not admit similar solutions. It should be noted that as a special case, Vajravelu and Shoewono [9] used $T_{w}=T_{\infty}+A x / L$ a linearly varying temperature distribution as the wall temperature, obtained similar boundary layer equations, and studied the uniqueness and existence of solutions for the mixed convection flow of a second-order fluid adjacent to a stretching sheet. Among the present available approaches for treating such problems, the similarity method is perhaps the one most frequently employed, owing to its conceptual and computational simplicity. Another advantage of the method is that the governing equations encountered in the course of its application can be treated as ordinary differential equations and are easy for solving. These equations become uncoupled when $G=0$, and the flow is regarded as a pure forced convective flow. We assume that a set of similar solutions of (2.9) and (2.12) can expand as power series in E. Following Bear and Walters [47], and assuming a small $E$, Let us define a parameter $E$ as

$$
E=\frac{k_{1}}{1+k_{1}}, \quad k_{1}>0
$$

Equation (2.14) gives

$$
k_{1}=\frac{E}{1-E}, \quad E>0
$$

From mathematical analysis, it is well known that

$$
k_{1}=\frac{E}{1-E}=E+E^{2}+E^{3}+\cdots .
$$

When $E \ll 1$, which is valid from (2.14), we assume that

$$
\begin{aligned}
& f(\eta)=f_{0}(\eta)+E f_{1}(\eta)+E^{2} f_{2}(\eta)+\cdots, \\
& \theta(\eta)=\theta_{0}(\eta)+E \theta_{1}(\eta)+E^{2} \theta_{2}(\eta)+\cdots
\end{aligned}
$$

Substituting (2.17) into (2.9)-(2.13) and equating coefficients of $E^{0}$ and $E^{1}$ (because $E$ is small, computing equations up to first-order of $E$ is adequate) result in 
(i) $\operatorname{order} E^{0}$ :

$$
\begin{gathered}
f_{0}^{\prime \prime \prime}+f_{0}^{\prime} f_{0}^{\prime \prime}-\left(f_{0}^{\prime}\right)^{2}+G \theta_{0}=0, \\
\theta_{0}^{\prime \prime}+\operatorname{Pr} f_{0} \theta_{0}^{\prime}-\operatorname{Pr} f_{0}^{\prime} \theta_{0}=0, \\
f_{0}=0, \quad f_{0}^{\prime}=1, \quad \theta_{0}=1 \quad \text { at } \eta=0, \\
f_{0}^{\prime}=0, \quad f_{0}^{\prime \prime}=0, \quad \theta_{0}=0 \quad \text { as } \eta \longrightarrow \infty .
\end{gathered}
$$

(ii) order $E^{1}$ :

$$
\begin{gathered}
f_{1}^{\prime \prime \prime}+f_{1} f_{0}^{\prime \prime}+f_{0} f_{1}^{\prime \prime}-2 f_{0}^{\prime} f_{1}^{\prime}-f_{0} f_{0}^{\prime \prime \prime \prime}-\left(f_{0}^{\prime \prime}\right)^{2}+2 f_{0}^{\prime} f_{0}^{\prime \prime \prime}+G \theta_{1}=0, \\
\theta_{1}^{\prime \prime}+\operatorname{Pr} f_{0} \theta_{1}^{\prime}+\operatorname{Pr} f_{1} \theta_{0}^{\prime}-\operatorname{Pr} f_{0}^{\prime} \theta_{0}^{\prime}-\operatorname{Pr} f_{1}^{\prime} \theta_{0}=0, \\
f_{1}(0)=0, \quad f_{1}^{\prime}(0)=0, \quad f_{1}^{\prime}=0 \quad \text { at } \eta=0, \\
\theta_{1}(0)=0, \quad \theta_{1}=0 \quad \text { as } \eta \longrightarrow \infty .
\end{gathered}
$$

From the numerical solution of the system for (2.18)-(2.19), we know the velocity and temperature fields and it is interesting to study the effects of the parameter $E$ on the rate of heat transfer. In terms of similarity parameters and dimensionless quantities defined by (2.8) and (2.11), the heating rate on the wall as

$$
q_{w}=-k\left(\frac{\partial \theta}{\partial y}\right)_{y=0}=-k \frac{B \sqrt{\mathrm{Re}_{x}}}{u_{\infty}}\left(T_{w}-T_{\infty}\right) \theta^{\prime}(0) .
$$

And the local Nusselt number $N u_{x}$ is defined by

$$
N u_{x}=\frac{h x}{k}=\frac{q_{w}}{T_{w}-T_{\infty}} \frac{x}{k}
$$

This expression can be written as

$$
N u_{x}=-\frac{B x}{u_{\infty}} \theta^{\prime}(0) \operatorname{Re}_{x}^{1 / 2}=-P_{e} \theta^{\prime}(0)
$$

The formulation of the first analysis principle for forced convection along a stretching sheet involves the energy conservation for the stretching sheet and the boundary layer equations for the flow. For a slender stretching sheet, ample evidence based on finitedifference solutions shows that a one-dimensional model is adequate. The stretching sheet temperature at any $x$ location serves as the wall temperature for the adjacent fluid and is denoted as $T_{f}(x)$. The energy equation for the stretching sheet may be written in two different forms, depending on how the coupled-fin/boundary-layer problem is solved. The method used here involves a succession of consecutive iteration solutions for the stretching sheet and the boundary-layer flow, with the sequence continued until there is no change (within a preset tolerance) between the $n$th iteration and the $(n-1)$ th iteration. Each iteration information data must be transferred from the boundary-layer 
solution, which is current for that period and is used as input to update the stretching sheet solution. This information may be either in the form of the local heat flux $q(x)$ or the local forced convective heat transfer coefficient $h(x)$. Both $q(x)$ and $h(x)$ are available from the current boundary layer solution. The stretching sheet energy equation can be expressed as

$$
\frac{d^{2} T_{f}}{d x^{2}}=\frac{q}{k_{f} t},
$$

or

$$
\frac{d^{2} T_{f}}{d x^{2}}=\left(\frac{h}{k_{f} t}\right)\left(T_{f}-T_{e}\right),
$$

in which $k_{f}$ is the thermal conductivity of the stretching sheet. For the solutions of either (2.23) or (2.24) at a given cycle of the iterative procedures, $h$ and $q$ can be regarded as known quantities. At first glance, it appears advantageous to use (2.24) rather than (2.23) because it is easier to solve; however (2.24) is employed in the solution scheme. This choice is made based on experience which has shown that at any stage of an iterative cycle $h$ is closer to the stretching sheet final converged result than $q$. Thus, (2.24) chooses to obtain rapid convergence of the iterative procedure, whereby this objective is satisfactorily fulfilled, as will be documented shortly. Equation (2.24) recasts in a dimensionless form by the substitutions

$$
X=\frac{x}{L}, \quad Y=\frac{y}{L}, \quad \theta_{f}=\frac{T_{f}-T_{e}}{T_{0}-T_{e}},
$$

where $T_{0}$ is the base temperature of the stretching sheet, so that

$$
\frac{d^{2} \theta_{f}}{d x^{2}}+\frac{d^{2} \theta_{f}}{d y^{2}}=\hat{h} N_{\mathrm{cc}} \theta_{f}
$$

with boundary conditions

$$
\theta_{f}=1 \quad(X=0) \quad \frac{d \theta_{f}}{d X}=0 \quad(X=1)
$$

where $N_{\mathrm{cc}}$ is the conduction-convection number and is defined as

$$
N_{\mathrm{cc}}=\left(\frac{k L}{k_{f}}\right) P_{e} .
$$

The quantity $\hat{h}$ is a dimensionless form of the local convective heat transfer coefficient and can be written as

$$
\widehat{h}=\left(\frac{h L}{k}\right) P_{e}^{-1} .
$$




\section{Numerical technique}

In the present problem, the set of similar equations (2.18)-(2.19) is linearlized by a perturbation analysis. These ordinary differential equations are discretized by a second-order accurate central difference method and a computer program has developed to solve these equations. To avoid errors in discretization and calculation processing and to ensure the convergence of numerical solutions, some conventional numerical procedures have been applied in order to choose a suitable grid size $\Delta \eta=0.05-0.1$, a suitable $\eta$ range, and a direct Gauss elimination method with Newton's method [48] used in the computer program to obtain solutions of the resulting difference equations. The Biot number is not an appropriate parameter in the present problem because the heat transfer coefficient varies with $x$ and is also unknown priorly at the beginning of the computations. These conjugate ordinary differential equations discretized by a second-order accurate central are as follows: difference method, and a computer program developed to solve these equations. Calculation steps of the entire conjugate system are as follows:

(1) estimate the stretching sheet temperature distribution $T_{f}(x)$;

(2) solve flow fields (2.18)-(2.19) and the local convective heat-transfer coefficient (2.29) according to the local Prandtl number, elastic parameter, and the local stretching sheet temperature from the related equations;

(3) solve the heat-conduction equation of the stretching sheet (2.26) with the renewed local convective heat-transfer coefficient;

(4) compute thermodynamic fluid properties from the stretching sheet temperature and free-stream temperature.

The sequences 2 to 4 are repeated until an acceptable convergence for stretching sheet temperature had been reached. The conditions of continuity in the heat flux and temperature at the fluid-solid interface are then satisfied and all relevant heat transfer characteristics can be calculated.

\section{Results and discussion}

The objective of the present analysis is to study the conjugate heat transfer of a stretching sheet cooled or heated by a high or low Prandtl number, second-grade viscoelastic fluid with various parameters. An extension of previous work is performed to investigate the conjugate heat transfer of a second-grade viscoelastic fluid past a stretching sheet. The model for grade-two fluids that is used in the momentum equations, the effects of dimensionless parameters, the Prandtl number $(\operatorname{Pr})$, the elastic number $(E)$, and the freeconvection parameter $(G)$ are main interests of the study. Flow and temperature fields of the stretching sheet flow are analyzed by utilizing the boundary layer concept to obtain a set of coupled momentum equations and energy equations. A similarity transformation and a series expansion method are used to convert the nonlinear, coupled partial differential equations to a set of nonlinear, coupled ordinary differential equations. A generalized derivation to analyze a stretching sheet flow has been studied. A second-order accurate finite-difference method has been used to obtain solutions of these equations. Table 4.1 is compared to $\theta^{\prime}(0)$ versus $\operatorname{Pr}, G$, and $m(E=0.0)$ with [49]. 
Table 4.1. Comparison $\theta^{\prime}(0)$ versus $\operatorname{Pr}, G$ and $m(E=0.0)$.

\begin{tabular}{l|cccc}
\hline $\operatorname{Pr}$ & $G$ & $m$ & $\theta^{\prime}(0)[49]$ & $\theta^{\prime}(0)$ present \\
\hline 0.73 & 0.1 & 0.5 & -0.470710 & -0.470446 \\
0.73 & 0. & 0.5 & -0.462114 & -0.462378 \\
0.73 & -1.0 & 0.5 & -0.452505 & -0.452799 \\
0.73 & -1.0 & 1.0 & -1.288098 & -1.288420 \\
0.73 & -1.0 & 1.5 & -2.023746 & -2.023430 \\
3.00 & 0.1 & 0.5 & -0.603917 & -0.603772 \\
3.00 & 0. & 0.5 & -0.599768 & -0.599364 \\
3.00 & -0.1 & 0.5 & -0.595436 & -0.595454 \\
3.00 & -0.1 & 1.0 & -1.783017 & -1.783570 \\
3.00 & -0.1 & 1.5 & -3.489231 & -3.489070 \\
\hline
\end{tabular}

From the comparison, we get very closely computation results with each other. Figure 2.1 is a sketch of the physical model for the conjugate heat transfer of a stretching sheet past a second-grade viscoelastic fluid. Figure 4.1 shows dimensionless velocity and velocity gradient, $f_{0}, f_{0}^{\prime}, f_{0}^{\prime \prime}$ versus $\eta$ as $G=1, E=0.001$, and $\operatorname{Pr}=1$. Figure 4.2 shows dimensionless velocity and velocity gradients $f_{1}, f_{1}^{\prime}, f_{1}^{\prime \prime}$ versus $\eta$ as $G=1, E=0.001$, and $\operatorname{Pr}=1$. Figures 4.1 and 4.2 are the dimensionless velocity and dimensionless velocity gradient distributions for the stretching sheet flow. For a mixed convection, the momentum and the energy are interacting with each other and the figure curves are all having a strong variation with $\eta$ along the boundary layer for different $G, \operatorname{Pr}$, and $E$. Figure 4.3 shows dimensionless temperature profiles $\theta^{\prime}(0)$ versus $\eta$ as $G=1, E=0.001$, and $\operatorname{Pr}=0.001,0.7,2,10$. Figure 4.4 shows dimensionless temperature profiles $\theta(0)$ versus $\eta$ as $G=1, E=0.0001$, and $\operatorname{Pr}=0.001,0.7,2,10$. Figure 4.5 shows dimensionless temperature gradient profiles $\theta^{\prime}(0)$ versus $\eta$ as $G=1, E=0.001$, and $\operatorname{Pr}=0.001,0.7$, 2 , 10. Figure 4.6 is shown dimensionless temperature profiles $\theta(0)$ versus $\eta$ as $G=1$, $E=0.001$, and $\operatorname{Pr}=0.001,0.7,2,10$. Figures 4.4 and 4.6 still indicate that for $\operatorname{Pr}=0.001$, the boundary layer thickness $\eta=13$ is not large enough. However, this being an extreme case, the dimensionless temperature profiles $\theta(0)$ are a little not smooth, we may use a larger $\eta$ to improve this problem. In this study, we have presented a nearly value $\eta=13$ for an extreme small $\eta$ case using only. Sometime may use a larger $\eta \geqq 13$ to obtain a more smooth curve for the small Prandtl number $\operatorname{Pr} \leqq 0.001$, it is an important phenomena in this study. Figure 4.7 shows dimensionless temperature gradient profiles $\theta^{\prime}(0)$ versus $\eta$ as $G=1, E=0.01$, and $\operatorname{Pr}=0.001,0.7,2,10$. Figure 4.8 shows dimensionless temperature profiles $\theta(0)$ versus $\eta$ as $G=1, E=0.01$, and $\operatorname{Pr}=0.001,0.7,2,10$ Figure 4.9 shows dimensionless temperature gradient profiles $\theta^{\prime}(0)$ versus $\eta$ as $G=1-25, E=0.001-0.15$, and $\operatorname{Pr}=1$. Figures 4.3-4.9 show the dimensionless temperature and dimensionless temperature gradient distribution for different parameters $G, \operatorname{Pr}$, and $E$. along the thermal boundary layer $\eta$. According to (2.22), $\theta^{\prime}(0)$ is an important factor for heat transfer phenomena. The value of $\theta^{\prime}(0)$ increased when $G, \operatorname{Pr}$, and $E$ increase. Therefore, the 


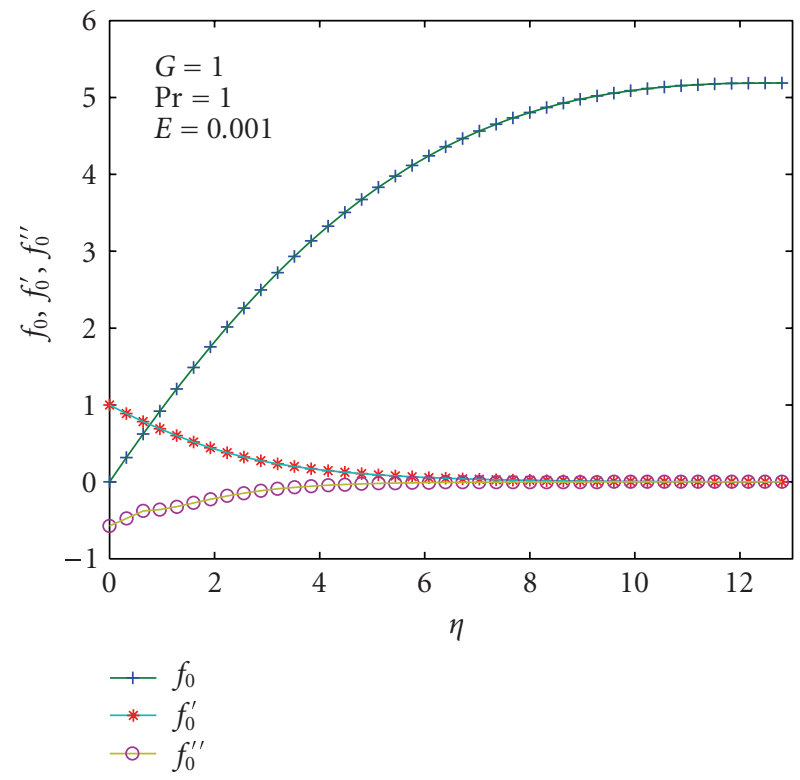

Figure 4.1. Dimensionless velocity and velocity gradients $f_{0}, f_{0}^{\prime}, f_{0}^{\prime \prime}$ versus $\eta$ as $G=1, E=0.001$, and $\operatorname{Pr}=1$.

heat transfer rate is positive proposing $G, \operatorname{Pr}$, and $E$ clearly. Figure 4.10 shows conjugate stretching sheet temperature distribution profiles $T_{w}-T_{\infty} / T_{0}-T_{\infty}$ versus $X$ as $G=1$, $E=0.0001$; Figure 4.11 is shown conjugate stretching sheet temperature distribution profiles $T_{w}-T_{\infty} / T_{0}-T_{\infty}$ versus $X$ as $G=10, E=0.0001$. Figure 4.12 is shown conjugate stretching sheet temperature distribution profiles $T_{w}-T_{\infty} / T_{0}-T_{\infty}$ versus $X$ as $G=1$, $10,50, E=0.0001$, and $m=1$. The conjugate stretching sheet temperature distributions along the stretching sheet with $E=0.0001$ are shown in Figures 4.10, 4.11, and 4.12 respectively. The tip temperature is lower and temperature gradients along the stretching sheet are higher with larger values of $N_{\mathrm{cc}}$ and $G$. These figures again indicate that the elastic nature of the fluid and a higher conductivity of the stretching sheet material can enhance the heat transfer performance of the stretching sheet. In addition, these figures indicate that higher $G$ values can enhance the heat transfer performance (higher local heat transfer coefficient), no matter how the $N_{\mathrm{cc}}$ varies. However, variations of $N_{\mathrm{cc}}$ from 0.5 to 2 have insignificant effect to the local heat transfer coefficient.

\section{Conclusion}

A steady two-dimensional mixed convection of an incompressible second-grade fluid adjacent to a stretching sheet is studied. A similar solution is obtained and results indicate that the buoyant force can accelerate the fluid speed in the boundary layer and enhance the heat transfer performance. The variation of the magnitude of dimensionless 


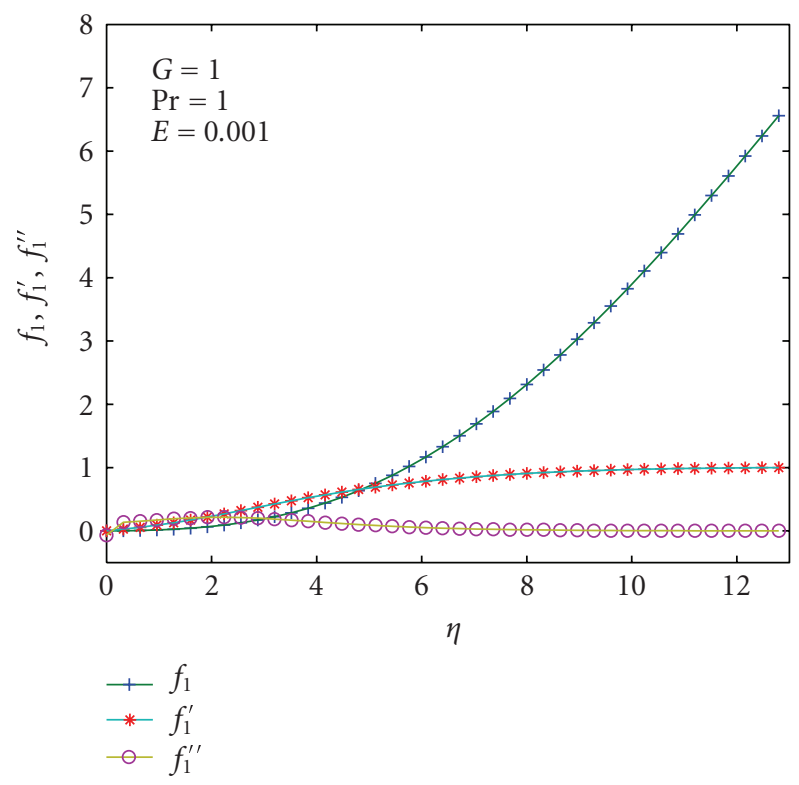

Figure 4.2. Dimensionless velocity and velocity gradients $f_{1}, f_{1}^{\prime}, f_{1}^{\prime \prime}$ versus $\eta$ as $G=1, E=0.001$, and $\operatorname{Pr}=1.0$.

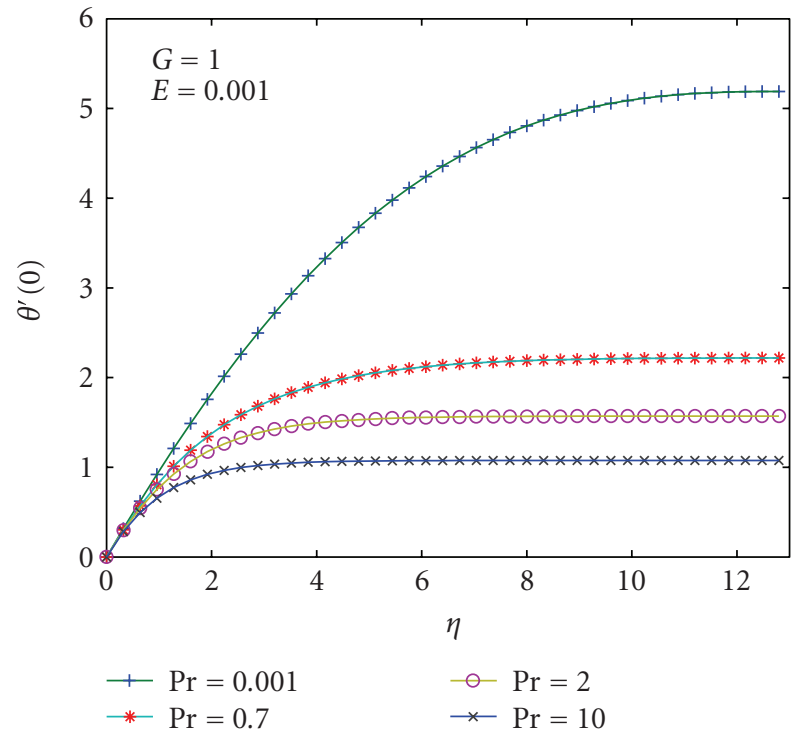

Figure 4.3. Dimensionless temperature profiles $\theta^{\prime}(0)$ versus $\eta$ as $G=1.0, E=0.001$ and $\operatorname{Pr}=$ $0.001,0.7,2.0,10.0$.

wall shear stress important factor $f^{\prime \prime}(0)$ depends on relative quantities of $E, G, f_{0}^{\prime}(0)$, and $f_{1}^{\prime}(0)$. Dimensionless heat transfer important factor $-\theta^{\prime}(0)$ increases with increasing 
14 Mathematical Problems in Engineering

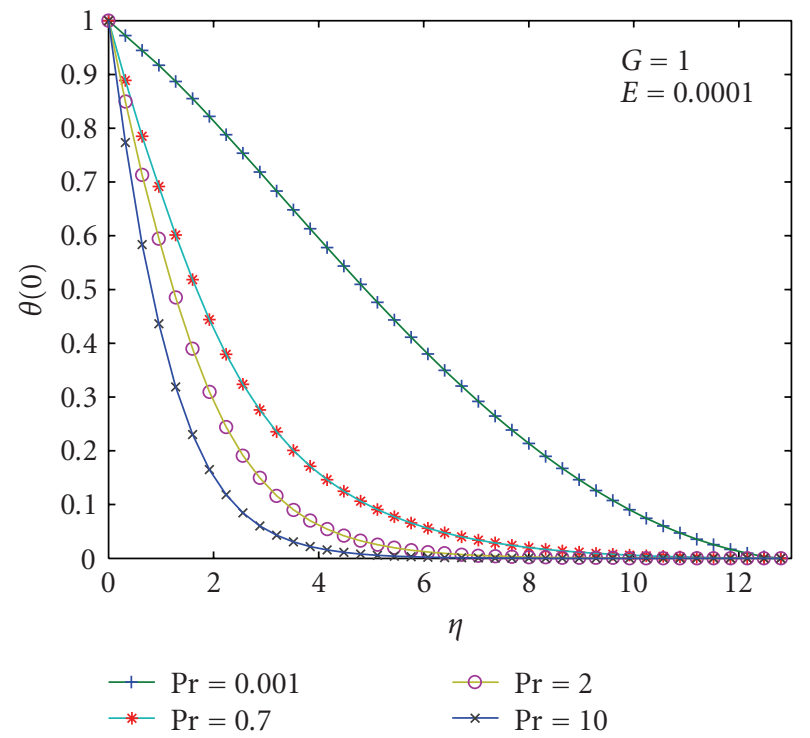

Figure 4.4. Dimensionless temperature profiles $\theta(0)$ versus $\eta$ as $G=1, E=0.0001$, and $\operatorname{Pr}=0.001,10$.

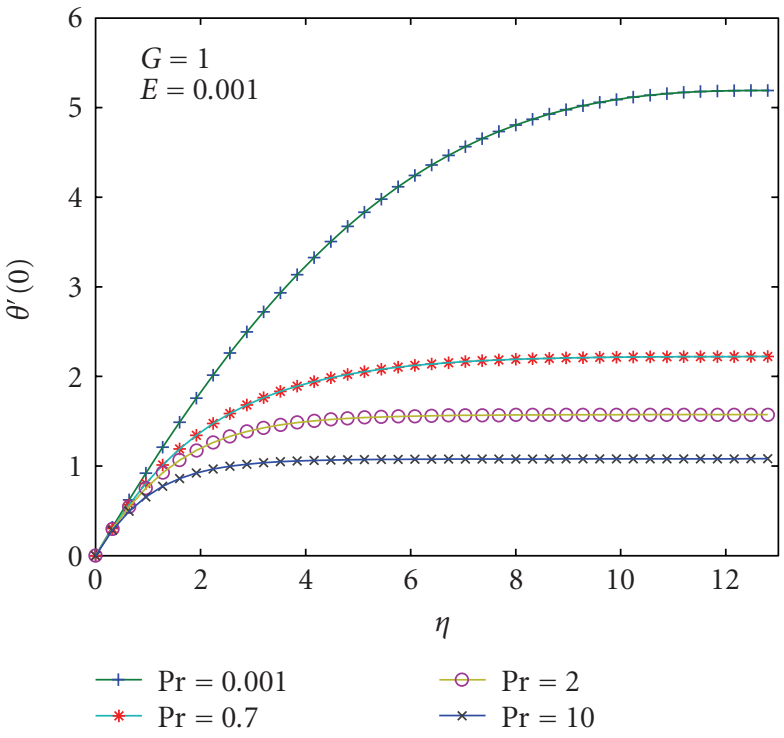

Figure 4.5. Dimensionless temperature gradient profiles $\theta^{\prime}(0)$ versus $\eta$ as $G=1, E=0.001$, and $\operatorname{Pr}=$ $0.001,0.7,2,10$.

values of $\operatorname{Pr}$ and/or $G,-\theta^{\prime}(0)$ is also increasing with increasing $E$. In the present study, we have introduced into analyses of a conjugate heat transfer problem of conduction in 


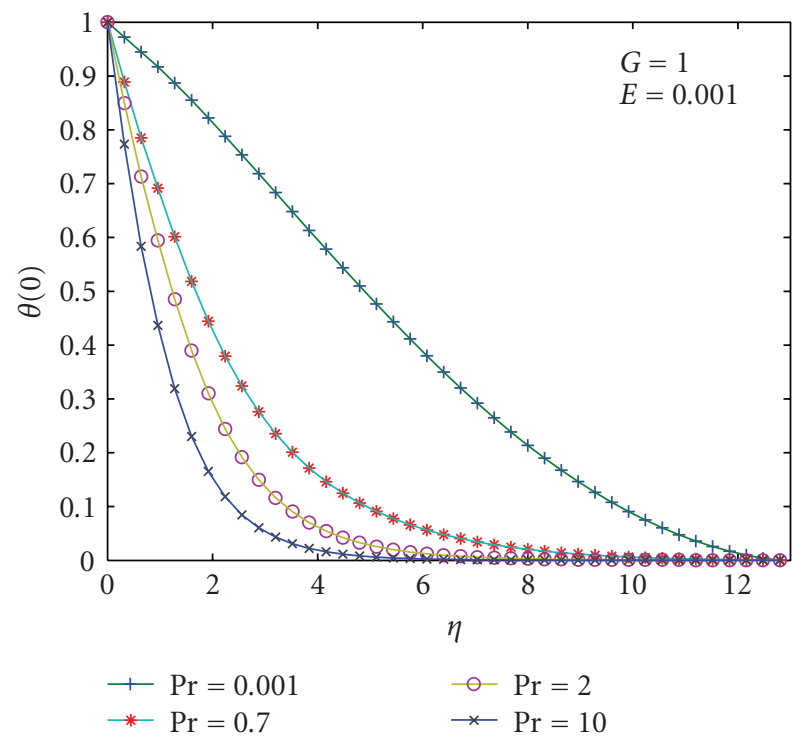

Figure 4.6. Dimensionless temperature profiles $\theta(0)$ versus $\eta$ as $G=1, E=0.001$, and $\operatorname{Pr}=0.001,10$.

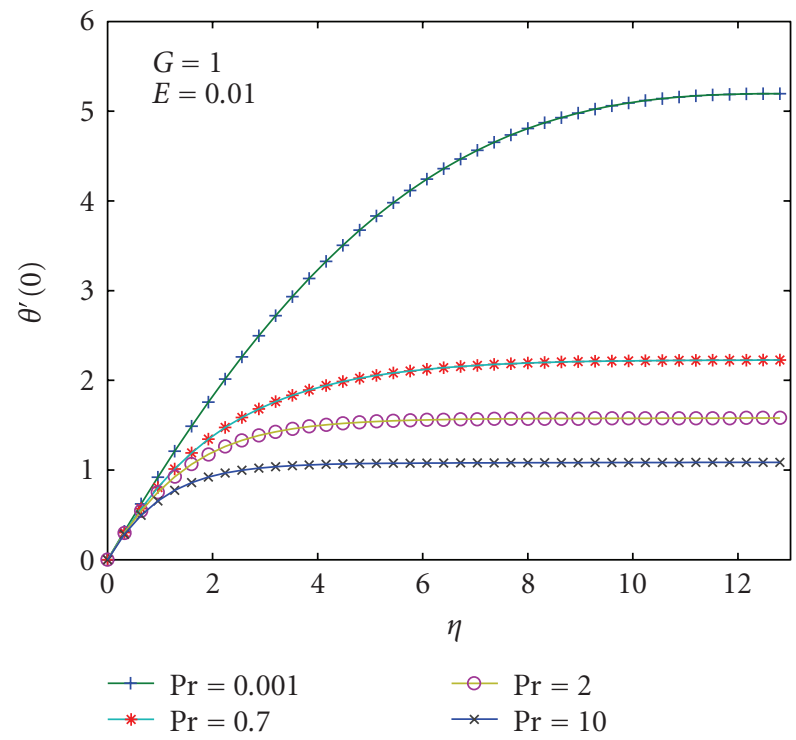

Figure 4.7. Dimensionless temperature gradient profiles $\theta^{\prime}(0)$ versus $\eta$ as $G=1, E=0.01$, and $\operatorname{Pr}=$ $0.001,0.7,2,10$.

a solid stretching sheet and a free convection in flow. The present conjugate problem is a hybrid system of the ordinary convective problem with a constant wall temperature. A lo- 
16 Mathematical Problems in Engineering

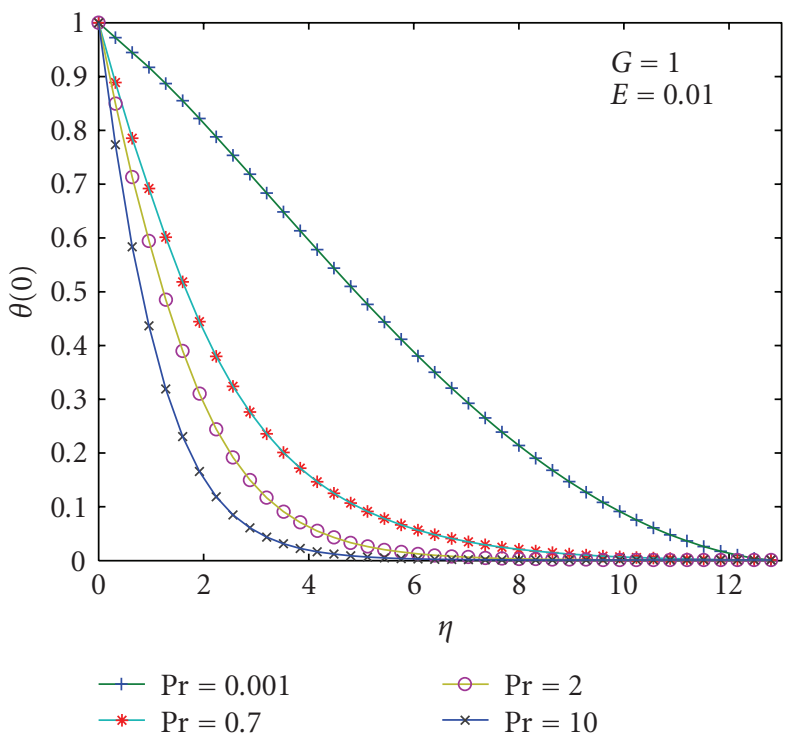

Figure 4.8. Dimensionless temperature profiles $\theta(0)$ versus $\eta$ as $G=1, E=0.01$, and $\operatorname{Pr}=$ $0.001,0.7,2,10$.

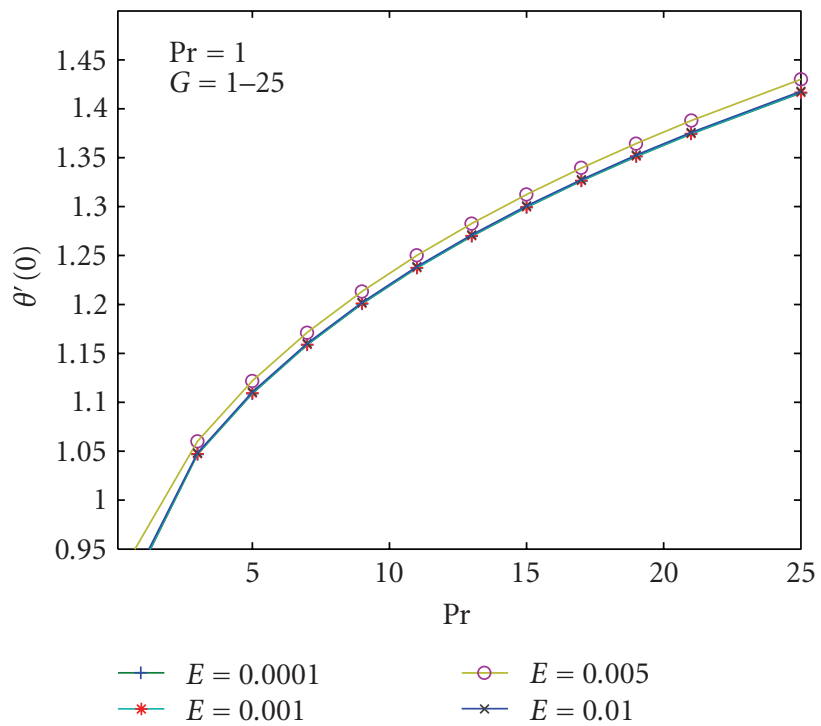

Figure 4.9. Dimensionless temperature gradient profiles $\theta^{\prime}(0)$ versus $\eta$ as $G=1-25, E=0.001-0.15$, and $\operatorname{Pr}=1$.

cal heat transfer coefficient is obtained from numerical solutions. Numerical results in the present study indicate that elastic effect $E$ in the flow can increase the local heat transfer 


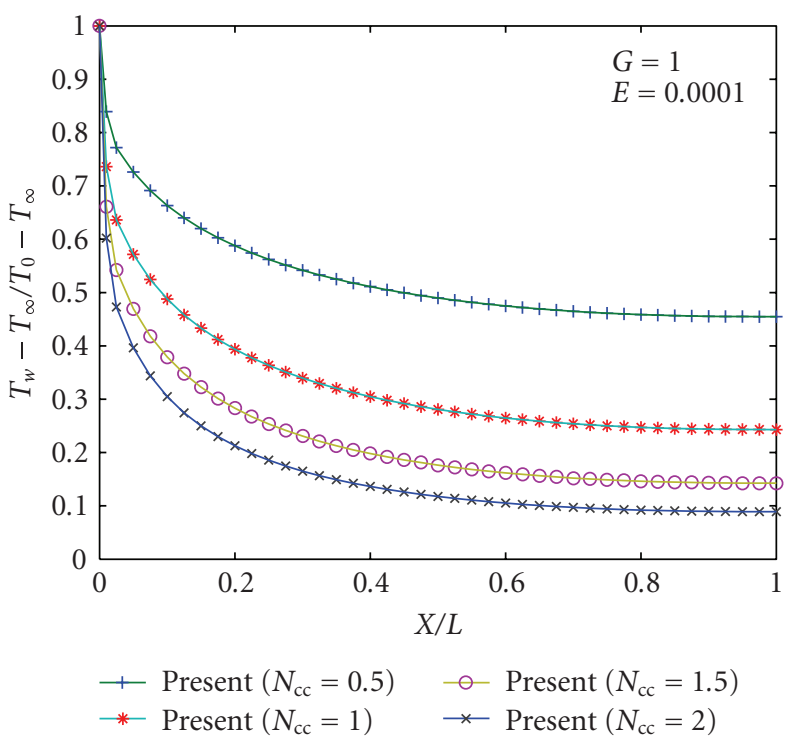

Figure 4.10. Conjugate stretching sheet temperature distribution profiles $T_{w}-T_{\infty} / T_{0}-T_{\infty}$ versus $X$ as $G=1, E=0.0001$.

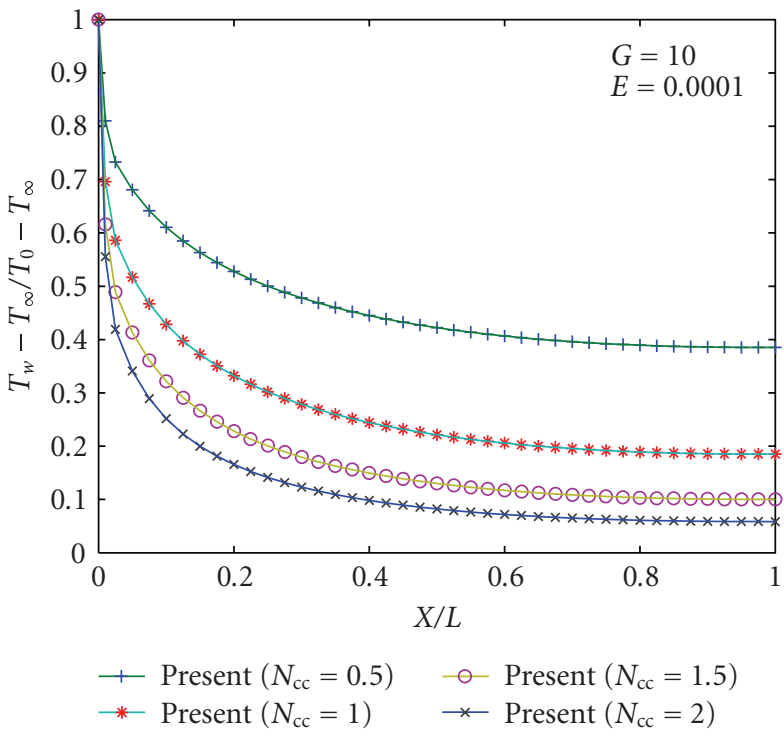

Figure 4.11. Conjugate stretching sheet temperature distribution profiles $T_{w}-T_{\infty} / T_{0}-T_{\infty}$ versus $X$ as $G=10, E=0.0001$.

coefficient and enhance the heat transfer of a stretching sheet. In addition, a better heat transfer is obtained with a larger $N_{\mathrm{cc}}, G$, and a larger $E$. 


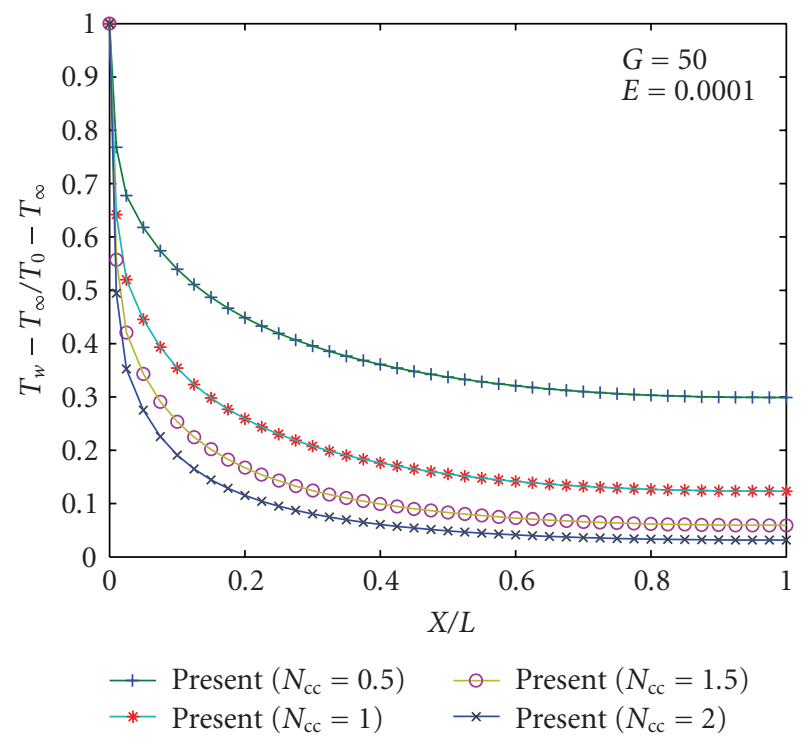

Figure 4.12. Conjugate stretching sheet temperature distribution profiles $T_{w}-T_{\infty} / T_{0}-T_{\infty}$ versus $X$ as $G=50, E=0.0001$.

\section{Acknowledgments}

The authors are grateful to the referees for useful comments. We are also thankful to the editor K. R. Rajagopal for his helpful reviewing jobs. On the other hand, the authors are also thankful to the financial support provided by Diwan College of Management.

\section{References}

[1] J. P. Hartnett, "Viscoelastic fluids: a new challenge in heat transfer," Journal of Heat Transfer, Transactions of ASME, vol. 114, no. 2, pp. 296-303, 1992.

[2] A. C. Srivatsava, "The flow of a non-Newtonian liquid near a stagnation point," Zeitschrift für Angewandte Mathematik und Physik, pp. 80-84, 1958.

[3] G. K. Rajeswari and S. L. Rathna, "Flow of a particular class of non-Newtonian viscoelastic and visco-inelastic fluids near a stagnation point," Zeitschrift für Angewandte Mathematik und Physik, vol. 13, pp. 43-57, 1962.

[4] S. P. Mishra and T. C. Panda, "Effect of injection on the flow of second order fluid in the inlet region of a channel," Acta Mechanica, vol. 32, no. 1-3, pp. 11-17, 1979.

[5] K. R. Rajagopal, A. S. Gupta, and T. Y. Na, "A note on the Falkner-Skan flows of a non-Newtonian fluid," International Journal of Non-Linear Mechanics, vol. 18, no. 4, pp. 313-320, 1983.

[6] M. Massoudi and M. Ramezan, "Effect of injection or suction on the Falkner-Skan flows of second grade fluids," International Journal of Non-Linear Mechanics, vol. 24, no. 3, pp. 221-227, 1989.

[7] C.-H. Hsu, C.-S. Chen, and J.-T. Teng, "Temperature and flow fields for the flow of a second grade fluid past a wedge," International Journal of Non-Linear Mechanics, vol. 32, no. 5, pp. $933-$ 946, 1997. 
[8] K. R. Rajagopal, "Boundary layers in non-linear fluids," in Trends in Applications of Mathematics to Mechanics (Lisbon, 1994), vol. 77 of Pitman Monographs and Surveys in Pure and Applied Mathematics, pp. 209-218, Longman, Harlow, UK, 1995.

[9] K. Vajravelu and E. Soewono, "Fourth order non-linear systems arising in combined free and forced convection flow of a second order fluid," International Journal of Non-Linear Mechanics, vol. 29, no. 6, pp. 861-869, 1994.

[10] V. K. Garg and K. R. Rajagopal, "Stagnation point flow of a non-Newtonian fluid," Mechanics Research Communications, vol. 17, no. 6, pp. 415-421, 1990.

[11] A. A. Raptis and H. S. Takhar, "Heat transfer from flow of an elastico-viscous fluid," International Communications in Heat and Mass Transfer, vol. 16, no. 2, pp. 193-197, 1989.

[12] B. C. Sakiadis, "Boundary-layer behaviour on continuous solid surfaces," American Institute of Chemical Engineers Journal, vol. 7, pp. 26-28, 1961.

[13] L. J. Crane, "Flow past a stretching plate," Zeitschrift für Angewandte Mathematik und Physik, vol. 21, no. 4, pp. 645-647, 1970.

[14] P. S. Gupta and A. S. Gupta, "Heat and mass transfer on a stretching sheet with suction or blowing," The Canadian Journal of Chemical Engineering, vol. 55, pp. 744-746, 1977.

[15] V. M. Soundalgekar, "Stokes problem for elastic-viscous fluid," Rheologica Acta, vol. 13, no. 2, pp. 177-179, 1974.

[16] B. Siddappa and B. S. Khapate, "Rivlin-Ericksen fluid flow past a stretching plate," Revue Roumaine des Sciences Techniques Série de Mécanique Appliquée, vol. 21, pp. 497-505, 1976.

[17] J. E. Danberg and K. S. Fansler, "A nonsimilar moving-wall boundary-layer problem," Quarterly of Applied Mathematics, vol. 34, pp. 305-309, 1976.

[18] K. R. Rajagopal, T. Y. Na, and A. S. Gupta, "Flow of a viscoelastic fluid over a stretching sheet," Rheologica Acta, vol. 23, no. 2, pp. 213-215, 1984.

[19] B. S. Dandapat and A. S. Gupta, "Flow and heat transfer in a viscoelastic fluid over a stretching sheet," International Journal of Non-Linear Mechanics, vol. 24, no. 3, pp. 215-219, 1989.

[20] R. Cortell, "Similarity solutions for flow and heat transfer of a viscoelastic fluid over a stretching sheet," International Journal of Non-Linear Mechanics, vol. 29, no. 2, pp. 155-161, 1994.

[21] K. R. Rajagopal, "On boundary conditions for fluids of the differential type," in Navier-Stokes Equations and Related Nonlinear Problems (Funchal, 1994), A. Sequeira, Ed., pp. 273-278, Plenum Press, New York, NY, USA, 1995.

[22] K. R. Rajagopal, "On the creeping flow of the second-order fluid," Journal of Non-Newtonian Fluid Mechanics, vol. 15, no. 2, pp. 239-246, 1984.

[23] K. R. Rajagopal and A. S. Gupta, "An exact solution for the flow of a non-Newtonian fluid past an infinite porous plate," Meccanica, vol. 19, no. 2, pp. 158-160, 1984.

[24] K. R. Rajagopal and P. N. Kaloni, "Some remarks on boundary conditions for flows of fluids of the differential type," in Continuum Mechanics and Its Applications (Burnaby, BC, 1988), G. A. C. Graham and S. K. Malik, Eds., pp. 935-942, Hemisphere, New York, NY, USA, 1989.

[25] J. E. Dunn and R. L. Fosdick, "Thermodynamics, stability, and boundedness of fluids of complexity 2 and fluids of second grade," Archive for Rational Mechanics and Analysis, vol. 56, pp. 191-252, 1974.

[26] V. Girault and L. R. Scott, "Analysis of a two-dimensional grade-two fluid model with a tangential boundary condition," Journal de Mathématiques Pures et Appliquées, vol. 78, no. 10, pp. 981-1011, 1999.

[27] M. Subhas Abel and P. H. Veena, "Viscoelastic fluid flow and heat transfer in a porous medium over a stretching sheet," International Journal of Non-Linear Mechanics, vol. 33, no. 3, pp. 531540, 1998. 
[28] M. Subhas Abel, A. Joshi, and R. M. Sonth, "Heat transfer in MHD viscoelastic fluid flow over a stretching surface," Zeitschrift für Angewandte Mathematik und Mechanik, vol. 81, no. 10, pp. 691-698, 2001.

[29] M. I. Char, "Heat and mass transfer in a hydromagnetic flow of the viscoelastic fluid over a stretching sheet," Journal of Mathematical Analysis and Applications, vol. 186, no. 3, pp. 674689, 1994.

[30] M. S. Sarma and B. N. Rao, "Heat transfer in a viscoelastic fluid over a stretching sheet," Journal of Mathematical Analysis and Applications, vol. 222, no. 1, pp. 268-275, 1998.

[31] R. Cortell, "A note on flow and heat transfer of a viscoelastic fluid over a stretching sheet," International Journal of Non-Linear Mechanics, vol. 41, no. 1, pp. 78-85, 2006.

[32] E. Sanjayanand and S. K. Khan, "On heat and mass transfer in a viscoelastic boundary layer flow over an exponentially stretching sheet," International Journal of Thermal Sciences, vol. 45, no. 8, pp. 819-828, 2006.

[33] S. K. Khan, "Heat transfer in a viscoelastic fluid flow over a stretching surface with heat source/sink, suction/blowing and radiation," International Journal of Heat and Mass Transfer, vol. 49, no. 3-4, pp. 628-639, 2006.

[34] W.-S. Yu and H.-T. Lin, "Conjugate problems of conduction and free convection on vertical and horizontal flat plates," International Journal of Heat and Mass Transfer, vol. 36, no. 5, pp. 1303-1313, 1993.

[35] E. M. Sparrow and M. K. Chyu, "Conjugate forced convection-conduction analysis of heat transfer in a plate fin," Journal of Heat Transfer, Transactions of ASME, vol. 104, pp. 204-206, 1982.

[36] B. Sundén, "The effect of Prandtl number on conjugate heat transfer from rectangular fins," International Communications in Heat and Mass Transfer, vol. 12, no. 3, pp. 225-232, 1985.

[37] A. V. Luikov, T. L. Perelman, and V. B. Rvskin, "On determination of the heat transfer coefficient in simultaneous conductive and convective heat transfer processes," in Proceedings of the 3rd International Heat transfer Conference, p. 12, Chicago, Ill, USA, August 1966.

[38] A. V. Luikov, V. A. Aleksashenko, and A. A. Aleksashenko, "Analytical methods of solution of conjugated problems in convective heat transfer," International Journal of Heat and Mass Transfer, vol. 14, no. 8, pp. 1047-1056, 1971.

[39] A. V. Luikov, Heat and Mass Transfer, Handbook, Energiya, Moscow, Russia, 1972.

[40] A. V. Luikov, "Conjugate convective heat transfer problems," International Journal of Heat and Mass Transfer, vol. 17, no. 2, pp. 257-265, 1974.

[41] B. Sundén, "Conjugate mixed convection heat transfer from a vertical rectangular fin," International Communications in Heat and Mass Transfer, vol. 10, no. 4, pp. 267-276, 1983.

[42] R. S. Rivlin and J. L. Ericksen, "Stress-deformation relations for isotropic materials," Journal of Rational Mechanics and Analysis, vol. 4, pp. 323-425, 1955.

[43] J. E. Dunn and K. R. Rajagopal, "Fluids of differential type: critical review and thermodynamic analysis," International Journal of Engineering Science, vol. 33, no. 5, pp. 689-729, 1995.

[44] H. Markovitz and B. D. Coleman, "Incompressible second-order fluids," in Advances in Applied Mechanics, vol. 8, pp. 69-101, Academic Press, New York, NY, USA, 1964.

[45] A. Acrivos, "A theoretical analysis of laminar natural convection heat transfer to non-Newtonian fluids," American Institute of Chemical Engineers Journal, vol. 6, pp. 584-590, 1960.

[46] K. R. Rajagopal, M. Ruzicka, and A. R. Srinivasa, “On the Oberbeck-Boussinesq approximation," Mathematical Models \& Methods in Applied Sciences, vol. 6, no. 8, pp. 1157-1167, 1996.

[47] D. W. Beard and K. Walters, "Elastico-viscous boundary-layer flows-I: two-dimensional flow near a stagnation point," Proceedings of the Cambridge Philosophical Society, vol. 60, pp. 667-674, 1964. 
[48] T. Cebeci and P. Bradshaw, Physical and Computational Aspects of Convective Heat Transfer, Springer, New York, NY, USA, 1984.

[49] K. Vajravelu, "Convection heat transfer at a stretching sheet with suction or blowing," Journal of Mathematical Analysis and Applications, vol. 188, no. 3, pp. 1002-1011, 1994.

Kai-Long Hsiao: Department of Network and Communication, Diwan College of Management, Diwan University, 87-1, Nansh Li, Madou Jen, Tainan 72153, Taiwan, China

Email address: hsiao.kailong@msa.hinet.net

Guan-Bang Chen: Department of Computer Science and Information Engineering, Diwan College of Management, Diwan University, 87-1, Nansh Li, Madou Jen, Tainan 72153, Taiwan, China Email address: gbchen@dwu.edu.tw 


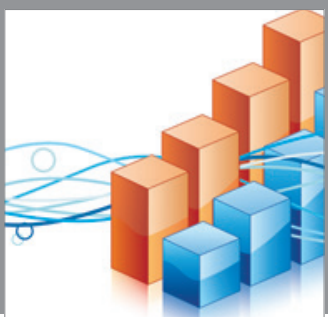

Advances in

Operations Research

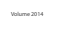

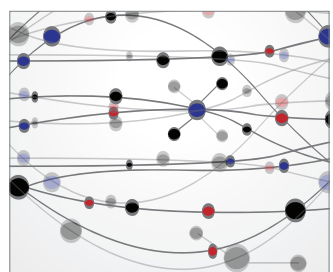

\section{The Scientific} World Journal
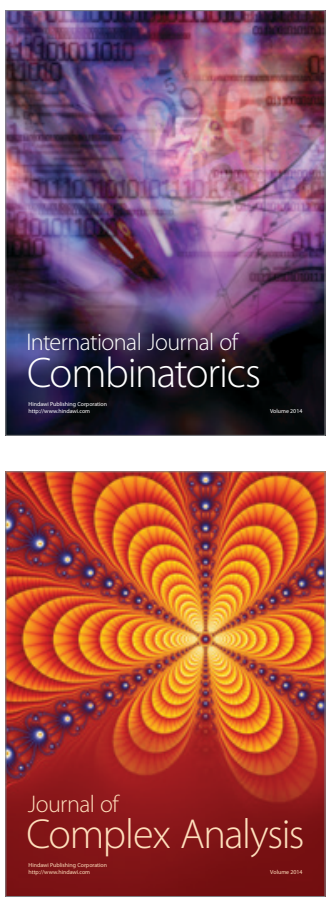

International Journal of

Mathematics and

Mathematical

Sciences
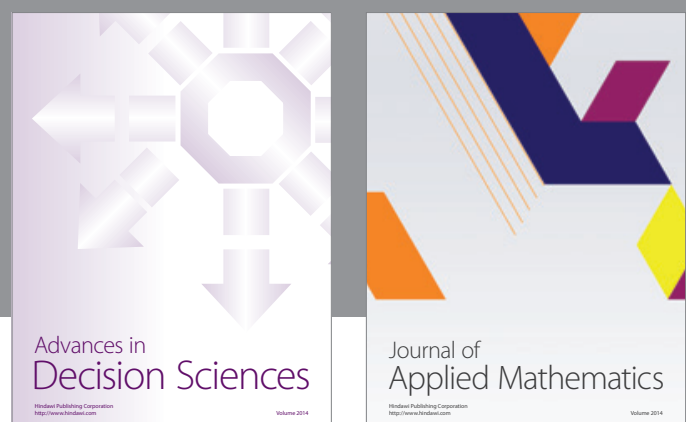

Journal of

Applied Mathematics
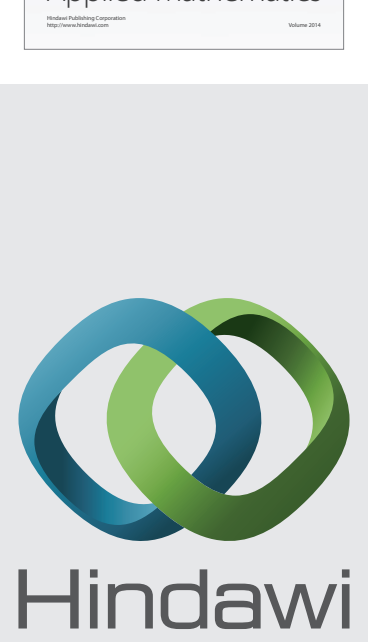

Submit your manuscripts at http://www.hindawi.com
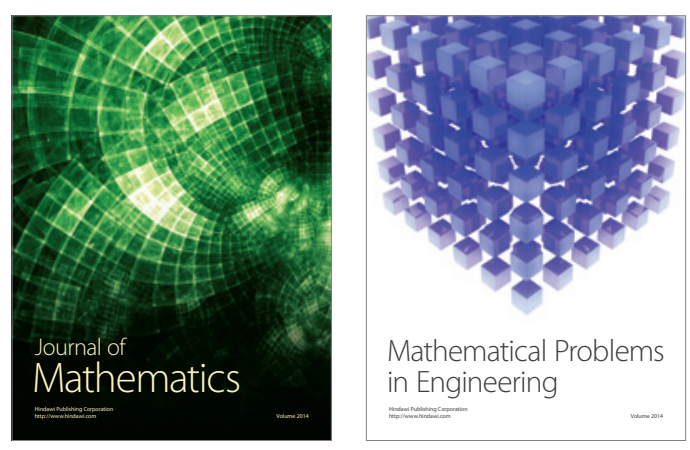

Mathematical Problems in Engineering
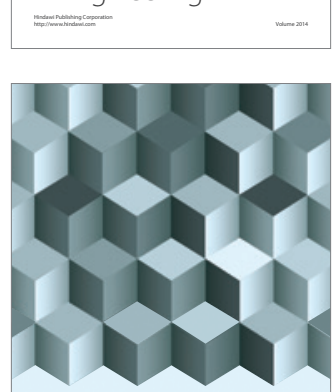

Journal of

Function Spaces
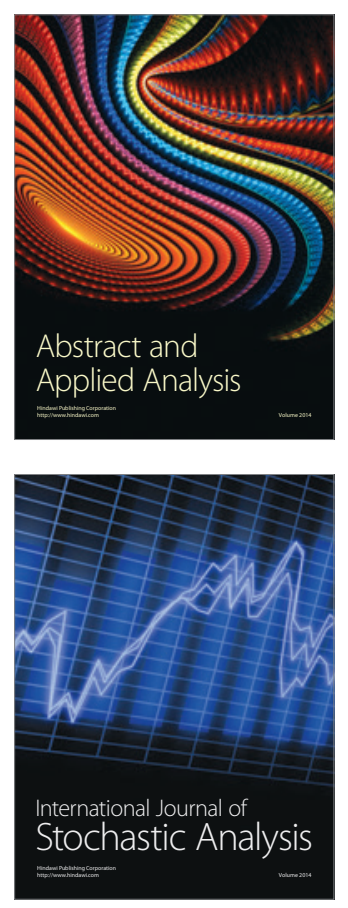

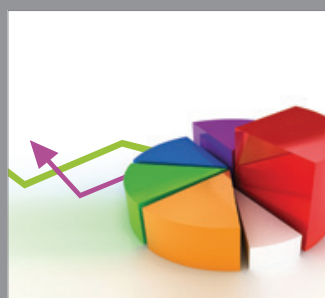

ournal of

Probability and Statistics

Promensencen
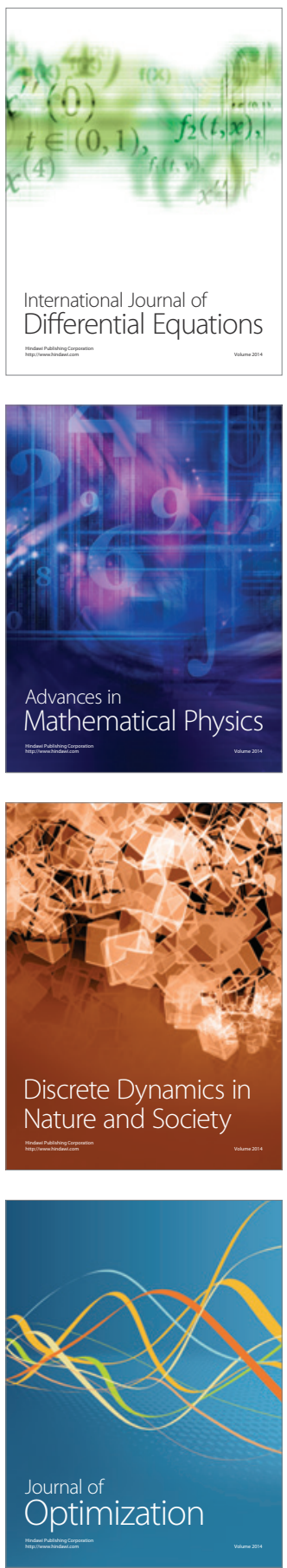